(2) Open Access Full Text Article

\title{
Sensory Hypersensitivity Severity and Association with Obsessive-Compulsive Symptoms in Adults with Tic Disorder
}

This article was published in the following Dove Press journal: Neuropsychiatric Disease and Treatment

\author{
David Isaacs (D) \\ Alexandra P Key $\mathbb{D D}^{2-4}$ \\ Carissa J Cascio (iD ${ }^{4-6}$ \\ Alexander C Conley $\mathbb{D}^{2,6}$ \\ Harrison C Walker $\mathbb{D}^{7}$ \\ Mark T Wallace iD $3,5,6,8,9$ \\ Daniel O Claassen (ID) \\ 'Department of Neurology, Vanderbilt \\ University Medical Center, Nashville, TN, \\ USA; ${ }^{2}$ Center for Cognitive Medicine, \\ Vanderbilt University Medical Center, \\ Nashville, TN, USA; ${ }^{3}$ Department of \\ Hearing and Speech Sciences, Vanderbilt \\ University, Nashville, TN, USA; \\ ${ }^{4}$ Vanderbilt Kennedy Center, Vanderbilt \\ University, Nashville, TN, USA; ${ }^{5}$ Frist \\ Center for Autism and Innovation, \\ Vanderbilt University, Nashville, TN, \\ USA; ${ }^{6}$ Department of Psychiatry and \\ Behavioral Sciences, Vanderbilt University \\ Medical Center, Nashville, TN, USA; \\ ${ }^{7}$ Department of Neurology, University of \\ Alabama at Birmingham, Birmingham, AL, \\ USA; ${ }^{8}$ Department of Pharmacology, \\ Vanderbilt University, Nashville, TN, \\ USA; ${ }^{9}$ Department of Psychology, \\ Vanderbilt University, Nashville, TN, USA
}

Background: Sensory hypersensitivity, defined as heightened awareness of and reactivity to external stimuli, is a bothersome symptom that affects up to $80 \%$ of adults with Tourette syndrome (TS). Such widespread prevalence suggests sensory hypersensitivity is a core feature of the disorder, but its severity and association with other clinical features of TS remain largely unexplored. Complicating matters, sensory hypersensitivity has been observed in two neurodevelopmental disorders commonly comorbid with TS: obsessive-compulsive disorder (OCD) and attention deficit hyperactivity disorder (ADHD).

Objective: We sought to measure sensory hypersensitivity in TS patients relative to healthy controls and to investigate the relationship of sensory hypersensitivity with OCD and ADHD symptoms in the context of TS.

Methods: We recruited 34 adults with TS or chronic tic disorder to undergo evaluation with the Yale Global Tic Severity Scale (YGTSS) and a battery of validated self-report instruments assessing sensory hypersensitivity (Sensory Gating Inventory, SGI; Sensory Perception Quotient, SPQ), premonitory urge (Premonitory Urge to Tic Scale, PUTS), OCD (Dimensional Obsessive-Compulsive Scale, DOCS), and ADHD (Adult ADHD SelfReport Screening Scale for DSM-5, ASRS-V). Age- and sex-matched healthy controls were recruited to complete SGI and psychiatric measures.

Results: SGI and SPQ scores strongly correlated $\left(r_{\mathrm{s}}=-0.73, p<0.0001\right)$ within patients. SGI total score was significantly higher in patients versus controls (119.0 vs $67.6, U=-5.3$, $p<0.0001$ ), indicating greater sensory hypersensitivity in the tic disorder group. SGI score correlated modestly with PUTS, DOCS, and ASRS-V scores but not with YGTSS total tic score. Hierarchical linear regression analysis revealed that, of the tested variables, only DOCS score contributed significantly to mean SGI score, with $\beta$ ranging from 1.03 ( $p=$ $0.044)$ to $1.41(p=0.001)$. A simple linear regression model with DOCS as the independent variable accounted for $31.9 \%$ of SGI score variance.

Conclusion: Sensory hypersensitivity is prominent in adults with tic disorder and is independently associated with obsessive-compulsive symptom severity.

Keywords: Tourette syndrome, tic disorder, sensory hypersensitivity, sensory sensitivity, obsessive-compulsive symptoms

\section{Introduction}

Bothersome sensory symptoms are common in Tourette syndrome (TS). ${ }^{1-3}$ The most widely recognized sensory symptom is premonitory urge, an unpleasant bodily sensation that waxes in the moments preceding a tic and typically wanes with execution of the tic. ${ }^{3}$ Premonitory urges are reported by $90 \%$ of adults and

\section{Department of Neurology, Vanderbilt}

University Medical Center, A-0II8

Medical Center North, Nashville, TN

37232, USA

Tel +I 6I5 936-0060

$\mathrm{Fax}+1615$ 936-1229

Email david.a.isaacs@vumc.org
Neuropsychiatric Disease and Treatment 2020:16 259|-260I

DovePress in $\mathbf{D}$ 
older children with $\mathrm{TS}^{3,4}$ and many patients find these more disturbing than the tics themselves. ${ }^{1}$

In addition to premonitory urges, as many as $80 \%$ of individuals with TS experience sensory hypersensitivity, defined as heightened awareness of and reactivity to external stimuli. ${ }^{1,5}$ Patients with sensory hypersensitivity describe, for example, enhanced perception of clothing rubbing against their skin; noise from electrical appliances; and intensity of ambient light. ${ }^{1,5}$ This heightened exteroceptive awareness is typically associated with avoidant behavior of provocative stimuli. Faint, repetitive sensations seem to be particularly grating. ${ }^{1,5}$ Although sensory hypersensitivity is endorsed by the vast majority with TS, patients actually exhibit normal detection thresholds for tactile, ${ }^{5,6}$ olfactory, ${ }^{5}$ and auditory stimuli. ${ }^{5}$ Higher-order sensory processing anomalies, however, have been identified in this population. $^{7-9}$ For example, children with TS habituate abnormally to repetitive tactile stimuli, ${ }^{7}$ and they process visual information differently than their typically developing peers. ${ }^{8}$ It remains unclear whether such higher-order sensory processing aberrations give rise, in full or in part, to the clinical phenomenon of sensory hypersensitivity. Studies exploring sensory processing in TS at the psychophysical or neurophysiologic level have yet to quantitatively evaluate for patient-reported sensory hypersensitivity, resulting in a translational knowledge gap.

Research into sensory hypersensitivity in TS patients has been predominantly confined to qualitative description. ${ }^{1,5}$ A single study has examined the severity of the clinical phenomenon in adults with TS, finding significantly increased extent of sensory hypersensitivity in patients relative to healthy controls. ${ }^{10}$ However, the study was limited by a small patient sample size ( 9 adults and 9 children). Thus, sparse quantitative, patient-reported data exists regarding sensory hypersensitivity in adults with TS. Sensory hypersensitivity is likely present in children with TS, but varied terminology and operational definitions in adult and pediatric studies pose major challenges for comparisons across age groups. ${ }^{9,11-13}$ Despite these ambiguities, the current body of evidence suggests that sensory hypersensitivity is an integral clinical feature of TS that is associated with diminished quality of life. ${ }^{9}$

Sensory hypersensitivity is not unique to TS. It has been reported in several other neurodevelopmental disorders, including obsessive-compulsive disorder (OCD) $)^{14-16}$ and attention deficit hyperactivity disorder (ADHD). ${ }^{17}$ Both OCD and ADHD are highly prevalent in TS, with respective lifetime rates of $50.0 \%$ and $54.3 \% .{ }^{18}$ Even TS patients not meeting formal diagnostic criteria for OCD or ADHD frequently exhibit symptoms of these disorders. ${ }^{19}$

The complexity of the TS phenotype makes it difficult to disentangle the relationship between sensory and psychiatric dimensions of the disorder. ${ }^{18}$ Conflicting results have emerged regarding associations between obsessivecompulsive symptoms and perceptual dysfunction in TS, with the sole study in adults failing to detect a relationship, ${ }^{10}$ but studies in children repeatedly demonstrating such a relationship. ${ }^{12,13}$ A single study in a pediatric TS sample found that children with dual diagnoses of ADHD and TS experienced more sensory processing dysfunction than children with TS alone; ${ }^{20}$ a similar study has yet to be conducted in adults with TS. Understanding the relationship of sensory hypersensitivity with OCD and ADHD symptomatology may sharpen definitions of clinically relevant TS subtypes and may facilitate transdiagnostic research into the neural basis of this shared phenomenon.

Thus, existing evidence suggests sensory hypersensitivity is a core clinical manifestation of TS and is possibly linked with comorbid OCD and/or ADHD. Here we sought to replicate, in a larger sample, previous findings showing increased sensory hypersensitivity in adults with TS relative to healthy controls. We also sought to examine the relationship of sensory hypersensitivity with OCD and ADHD symptoms in adults with TS. We recruited adult patients with TS or chronic tic disorder, as well as ageand sex-matched healthy controls, to complete a battery of validated, self-report rating scales assessing sensory hypersensitivity and common TS psychiatric comorbidities. Patients were also administered the Yale Global Tic Severity Scale (YGTSS) and the Premonitory Urge to Tic Scale (PUTS). We hypothesized that patients would endorse significantly more sensory hypersensitivity compared to controls. Given the known link between sensory hypersensitivity and obsessive-compulsive symptoms in other populations, we further hypothesized that severity of sensory hypersensitivity among patients would positively correlate with obsessive-compulsive symptoms.

\section{Methods}

\section{Participants}

Between April 2019 and May 2020, we prospectively recruited 34 adults $(>18$ years of age) with TS $(n=32)$ or chronic (motor or vocal) tic disorder $(n=2)$ from Vanderbilt University Medical Center (VUMC) Tourette 
Syndrome Clinic and from VUMC research registries. Tic disorders were diagnosed according to Diagnostic and Statistical Manual of Mental Disorders, 5th edition (DSM-5) criteria. Notably, evidence indicates chronic motor tic disorder (defined as one or more motor tics but no vocal tics, persistent for more than one year with tic onset before 18) and chronic vocal tic disorder (defined as one or more vocal tics but no motor tics, persistent for more than one year with tic onset before 18) exist on a common clinical continuum with TS (defined as at least two motor tics and one vocal tic, persistent for more than one year with tic onset before 18), with chronic motor tic disorder and chronic vocal tic disorder being less severe forms of $\mathrm{TS}^{21}$ In this article, the term "tic disorder" encompasses chronic motor tic disorder, chronic vocal tic disorder, and TS.

A non-clinical sample of healthy adult controls was recruited through ResearchMatch. ResearchMatch is a web-based recruitment registry designed to link investigators with volunteers interested in clinical research; volunteers are notified of new research studies for which they may qualify based on self-reported demographic and medical information. ${ }^{22}$ For this study, individuals with no reported history of neurologic or psychiatric diagnoses were recruited through this platform. Once enrolled, controls completed assessments online and were not interviewed or examined in person. Patients and healthy controls were one-to-one matched on sex and age $( \pm 3$ years).

All participants were required to have capacity for providing informed consent and to speak English (given the validated scales employed). All participants gave informed consent electronically prior to engaging in any study-related activity. This study was approved by the VUMC Institutional Review Board and was conducted in accordance with the Declaration of Helsinki.

\section{Measures}

Table 1 summarizes the rating scales used in this study. The YGTSS was administered to all patients by a neurologist experienced with the scale (D.I.). Patients were then invited to complete a battery of self-report rating scales in Research Electronic Data Capture (REDCap), a secure online, HIPPA-compliant research database. ${ }^{23,24}$ Median time between YGTSS and completion of self-report scales was 8.5 days (range $0-100$ days). Controls completed an identical battery, except they were not asked to complete TS-specific scales or the Sensory
Table I Clinical Rating Scales

\begin{tabular}{|c|c|c|c|}
\hline Scale Name & $\begin{array}{l}\text { \# of } \\
\text { Scale } \\
\text { Items }\end{array}$ & $\begin{array}{l}\text { Scale } \\
\text { Range }\end{array}$ & Score Interpretation \\
\hline $\begin{array}{l}\text { Sensory Gating } \\
\text { Inventory }(\mathrm{SGI})^{25}\end{array}$ & 36 & $0-216$ & $\begin{array}{l}\text { Higher scores indicate } \\
\text { more abnormal sensory } \\
\text { gating experiences }\end{array}$ \\
\hline $\begin{array}{l}\text { Sensory Perception } \\
\text { Quotient (SPQ) }{ }^{26 *}\end{array}$ & 35 & $0-105$ & $\begin{array}{l}\text { Lower scores indicate } \\
\text { greater sensory } \\
\text { hypersensitivity }\end{array}$ \\
\hline $\begin{array}{l}\text { Dimensional } \\
\text { Obsessive- } \\
\text { Compulsive Scale } \\
(\mathrm{DOCS})^{28}\end{array}$ & 20 & $0-80$ & $\begin{array}{l}\text { Higher scores indicate } \\
\text { more obsessive- } \\
\text { compulsive symptoms }\end{array}$ \\
\hline $\begin{array}{l}\text { Adult ADHD Self- } \\
\text { Report Screening } \\
\text { Scale for DSM-5 } \\
(\text { ASRS-V) } 54\end{array}$ & 6 & $0-24$ & $\begin{array}{l}\text { Higher scores indicate } \\
\text { more ADHD } \\
\text { symptoms }\end{array}$ \\
\hline $\begin{array}{l}\text { Generalized Anxiety } \\
\text { Disorder } 7 \text { (GAD- } \\
7)^{55}\end{array}$ & 7 & $0-21$ & $\begin{array}{l}\text { Higher scores indicate } \\
\text { more anxiety }\end{array}$ \\
\hline $\begin{array}{l}\text { Patient Health } \\
\text { Questionnaire } 9 \\
(\text { PHQ-9) }\end{array}$ & 9 & $0-27$ & $\begin{array}{l}\text { Higher scores indicate } \\
\text { more depression }\end{array}$ \\
\hline $\begin{array}{l}\text { Premonitory Urge to } \\
\text { Tic Scale (PUTS) }{ }^{27 *}\end{array}$ & 10 & $9-36$ & $\begin{array}{l}\text { Higher scores indicate } \\
\text { more severe } \\
\text { premonitory urge }\end{array}$ \\
\hline $\begin{array}{l}\text { YGTSS Total Tic } \\
\text { Score }^{57 *}\end{array}$ & 10 & $0-50$ & $\begin{array}{l}\text { Higher scores indicate } \\
\text { more severe tics; the } \\
\text { total score is } \\
\text { comprised of two } \\
\text { subscales: motor tic } \\
\text { score }(0-25) \text { and } \\
\text { phonic tic score }(0-25)\end{array}$ \\
\hline
\end{tabular}

Note: *Administered to patients only.

Perception Quotient (SPQ). All participants were asked to start and finish the battery of self-report scales in a single sitting.

The primary outcome of interest was the Sensory Gating Inventory (SGI), a self-report measure of "sensory gating-like subjective experiences" developed and validated in healthy controls. ${ }^{25}$ For this instrument, respondents rate 36 statements about sensory perception on a six-point Likert scale from "never true" to "always true." Higher total score signifies more abnormal sensory gating experience. No established scale cutoffs delineate normal from abnormal sensory perception. The SGI is 
comprised of four domains, identified by confirmatory factor analysis: Perceptual Modulation, Distractibility, Over-Inclusion and Hyperawareness, and Fatigue and Stress Vulnerability. ${ }^{25}$ Domain scores were calculated for this study. As no accepted gold standard scale exists for quantifying sensory hypersensitivity, the SGI was selected as the primary outcome because it was rigorously developed ( $n>1000$ participants) and validated ( $n>800$ participants) in large sample populations, with systematic assessment for scale test-retest reliability, factor structure, convergent and discriminant validity, and sex differences. ${ }^{25}$ Notably, the scale showed good convergent validity with the Highly Sensitive Person Scale $(r=0.65$, $p<0.001, n=219),{ }^{25}$ another measure of sensory sensitivity. Furthermore, the scale has previously been administered in a TS sample. ${ }^{10}$

Because no accepted gold standard measure of sensory hypersensitivity exists, a second sensory hypersensitivity scale, the SPQ, was also administered to patients in order to test convergent validity of the SGI in a population with chronic tic disorders. The SPQ is a self-report questionnaire validated in healthy adults and in adults with autism spectrum disorder. ${ }^{26}$ Respondents use a four-point Likert scale to rate level of agreement on 35 statements about basic sensory perception, with 29 items devoted to hypersensitivity and six devoted to hyposensitivity. The hyposensitivity items are reverse-scored. Lower total SPQ score indicates greater sensory hypersensitivity. As with the SGI, no established score thresholds distinguish normal from abnormal sensory perception. The SPQ has also undergone careful development and validation, with assessment for scale factor structure, convergent validity, and sex differences. ${ }^{26}$

Tic disorder patients were also administered the PUTS, a widely used 10-item self-report survey quantifying severity of premonitory urge. ${ }^{27}$ Item 10 asks patients to rate tic suppressibility and, in accord with prior studies, is not included in the total score given its lack of correlation with the remainder of the scale items and its intended measurement of a distinct construct (tic suppressibility as opposed to premonitory urge). ${ }^{27}$ Higher total PUTS score indicates more severe premonitory urge(s).

To ascertain the impact of psychiatric comorbidities on sensory phenomena, validated self-report scales for OCD, ADHD, depression, and anxiety were included in the assessment battery. Dimensional Obsessive-Compulsive Scale (DOCS) score cutoff of $\geq 21$ provides $70 \%$ sensitivity and $70 \%$ specificity in discriminating OCD from other anxiety disorders. ${ }^{28}$ Adult ADHD SelfReport Screening Scale for DSM-5 (ASRS-V) score cutoff of $\geq 14$ provides $81 \%$ sensitivity and $70 \%$ specificity in identifying ADHD in clinical populations. ${ }^{29}$

\section{Statistics}

To evaluate scale internal consistency, Cronbach's $\alpha$ was computed for all self-report measures. A threshold of 0.70 was deemed the minimum acceptable reliability. ${ }^{30}$ Spearman's rank correlation $\left(r_{\mathrm{s}}\right)$ was used to assess convergent validity of SGI and SPQ measures, as well as to quantify the association between other clinical rating scales. Between-group comparisons of variables were conducted with Wilcoxon-rank sum test statistic $(U)$. Effect size of between-group differences was also quantified with the Wilcoxon-rank sum statistic. ${ }^{31}$

To determine the potential modifying influence of OCD and ADHD symptoms on sensory hypersensitivity, two approaches were taken. First, the subset of tic disorder patients $(n=11)$ who screened negative for OCD (DOCS score $<21$ ) and ADHD (ASRS score < 14) were compared to age- and sex-matched healthy controls. Second, hierarchical linear regression analysis, with backwards elimination, was conducted with patient data to identify variables independently associated with SGI score. Independent variables included in the first model included age, sex, YGTSS total tic score, DOCS score, and ASRS-V score. Initial regression diagnostics included assessment for outliers, defined as observations with Cook's $D$ value $>4 / n$. Three outliers were identified and removed from the first model and from all subsequent nested models in the hierarchical regression analysis. Additional regression diagnostics included assessments for normality of residuals (using Shapiro-Wilk test of residuals), heteroscedasticity (by application of BreuschPagan test), and multicollinearity (defined as variance inflation factor $(V I F)>10)$. These procedures were repeated iteratively for each model in the hierarchical regression analysis. Because $\mathrm{OCD}^{14,15}$ and $\mathrm{ADHD}^{17}$ have been associated with altered sensory perception, DOCS and ASRS-V were pre-specified to be the last two independent variables in the nested models. Interactions between independent variables were not included in the regression analysis due to the study sample size. Model goodness-of-fit was indicated by $R^{2}$, and model quality was further measured by Akaike information criteria (AIC). For a given model of a dependent variable, lower AIC values signify less information loss, ie superior model quality. ${ }^{32}$

Data were complete for each participant on all scales except GAD-7. For this scale, two controls failed to answer one item, and one patient failed to answer two items. Predictive mean matching was used to impute these missing values. For all calculations, the Type 1 error rate threshold 
was set at 0.05 . Given the exploratory nature of the study, error rate thresholds were not corrected for multiple comparisons. Statistical analyses were performed in STATA.

\section{Results}

Demographic and clinical characteristics of patients and controls are shown in Table 2 .

\section{Reliability and Convergent Validity of SGI and SPQ}

SGI exhibited excellent internal reliability in controls and patients, with Cronbach's $\alpha$ of 0.92 and 0.97 , respectively. Within tic disorder patients, Cronbach's $\alpha$ was 0.92 for SPQ. SGI and SPQ total scores strongly correlated

Table 2 Population Characteristics

\begin{tabular}{|c|c|c|}
\hline & $\begin{array}{l}\text { Tic Disorder } \\
\text { Patients }\end{array}$ & $\begin{array}{l}\text { Healthy } \\
\text { Controls }\end{array}$ \\
\hline $\operatorname{Sex}(M: F)$ & $24: 10$ & $24: 10$ \\
\hline Age (years) & $33.5(22-49)^{\wedge}$ & $33(23-48)$ \\
\hline \multicolumn{3}{|l|}{ Ethnicity } \\
\hline Hispanic or Latino & 0 & 2 \\
\hline Not Hispanic or Latino & 34 & 30 \\
\hline Unknown/not reported & 0 & 2 \\
\hline \multicolumn{3}{|l|}{ Race } \\
\hline Asian & I & 2 \\
\hline Black or African American & 0 & 2 \\
\hline White & 32 & 28 \\
\hline More than one race & 1 & 2 \\
\hline \multicolumn{3}{|l|}{ Self-reported history of: } \\
\hline OCD & 18 & 0 \\
\hline ADHD & 9 & 0 \\
\hline Anxiety & 24 & 0 \\
\hline Depression & 24 & 0 \\
\hline Autism spectrum disorder & 0 & 0 \\
\hline Impulse control disorder & 3 & 0 \\
\hline \multicolumn{3}{|l|}{$\begin{array}{l}\text { Self-reported current use of } \\
\text { psychotropic medications: }\end{array}$} \\
\hline None & 5 & 32 \\
\hline SSRI and/or SNRI & 20 & 0 \\
\hline Benzodiazepine & 9 & 0 \\
\hline Antipsychotic & 9 & 0 \\
\hline Mood stabilizer $^{+}$ & 6 & 0 \\
\hline$\alpha$-Agonist & 3 & 0 \\
\hline Stimulant & 3 & 0 \\
\hline Not reported & 0 & 2 \\
\hline
\end{tabular}

Notes: ^Median (interquartile range). ${ }^{+}$In this sample, mood stabilizers used included lamotrigine, oxcarbazepine, and/or lithium.

Abbreviations: SSRI, selective serotonin reuptake inhibitor; SNRI, serotoninnorepinephrine reuptake inhibitor. $\left(r_{\mathrm{s}}=-0.73, p<0.0001\right)$ in patients, supporting convergent validity of these scales in tic disorder populations (see Figure 1). Cronbach's $\alpha$ for all other self-report measures is provided in the Supplemental Material. Of the four SGI domains, SPQ most strongly correlated with Over-Inclusion and Hyperawareness $\left(r_{\mathrm{s}}=-0.78, p<0.0001\right)$, followed by Distractibility $\left(r_{\mathrm{s}}=-0.68, p<0.0001\right)$, Perceptual Modulation $\left(r_{\mathrm{s}}=-0.62, p=0.0001\right)$, and Fatigue and Stress Vulnerability $\left(r_{\mathrm{s}}=-0.62, p=0.0001\right)$.

\section{Contrasts Between Tic Disorder Patients and Controls}

SGI score significantly differed between patients and controls (see Table 3). Of patients, $67.6 \%$ had SGI total scores two standard deviations higher than the control mean. Based on the Wilcoxon-rank sum statistic, patients were $87.4 \%$ (95\% CI: 78.7-96.2\%) more likely to have a higher SGI score than controls. Patients had significantly higher scores than controls on each of the four SGI subscales. When comparing the subset of tic disorder patients who screened negative for OCD and ADHD $(n=11)$ to their age- and sex-matched controls, SGI scores still significantly diverged: 100.1 (36.3) versus 63.6 (11.0), $U=-2.7, p<0.01$. Notably, matched patients and controls in this subanalysis did not differ by DOCS total (10.6 (5.3) and 8.4 (4.3), $U=-1.3, p=0.21$ ) but did differ by ASRSV score (9.64 (1.86) and 5.18 (2.48), $U=-3.4, p<0.001)$.

\section{Within Tic Disorder Patient Analysis}

Correlations between scales for tic disorder patients are displayed in Table 4. SGI and SPQ correlations with psychiatric scales were similar so only SGI correlations are presented. SGI scores correlated modestly with PUTS,

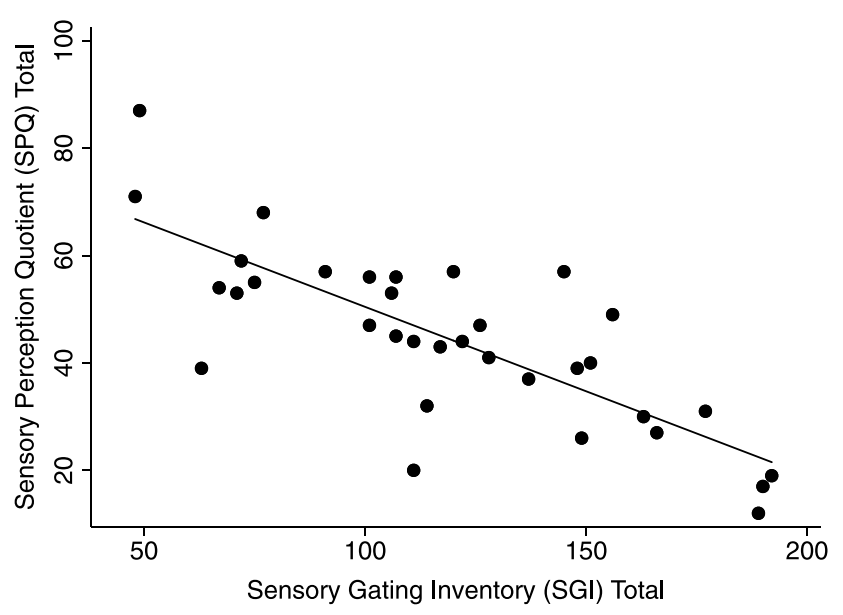

Figure I Scatterplot of SGI scores versus SPQ scores. 
Table 3 Scale Scores for Tic Disorder Patients and Healthy Controls

\begin{tabular}{|c|c|c|c|c|}
\hline Scale Name & $\begin{array}{l}\text { Tic Disorder } \\
\text { Patients }\end{array}$ & $\mathrm{HC}$ & $\begin{array}{l}\text { Wilcoxon Rank Sum Statistic } \\
\text { (U) }\end{array}$ & $p$-value \\
\hline SGI Total & $\begin{array}{l}\text { II } 9.0(40.5) \\
\mid I 5.5(9|-| 49)^{*}\end{array}$ & $\begin{array}{l}67.6(19.0) \\
64.5 \\
(54-78)\end{array}$ & -5.3 & $<0.0001$ \\
\hline SGI Subscale for Perceptual Modulation & $\begin{array}{l}43.6(17.7) \\
43.5(30-56)\end{array}$ & $\begin{array}{l}22.1(6.4) \\
20(18-27)\end{array}$ & -5.3 & $<0.0001$ \\
\hline SGI Subscale for Distractibility & $\begin{array}{l}31.9(10.2) \\
33(24-4 I)\end{array}$ & $\begin{array}{l}19.5(8.9) \\
18.5 \\
(12-25)\end{array}$ & -4.5 & $<0.0001$ \\
\hline $\begin{array}{l}\text { SGI Subscale for Over-Inclusion and } \\
\text { Hyperawareness }\end{array}$ & $\begin{array}{l}24.5(9.6) \\
25.5(18-32)\end{array}$ & $\begin{array}{l}14.8(6.0) \\
13(11-19)\end{array}$ & -4.0 & 0.0001 \\
\hline SGI Subscale for Fatigue and Stress Vulnerability & $\begin{array}{l}19.0(6.9) \\
18.5(14-25)\end{array}$ & $\begin{array}{l}11.3(4.4) \\
10(8-15)\end{array}$ & -4.5 & $<0.0001$ \\
\hline SPQ & $\begin{array}{l}44.5(16.3) \\
44.5(32-56)\end{array}$ & - & - & - \\
\hline PUTS & $\begin{array}{l}24.9(4.9) \\
25(22-29)\end{array}$ & - & - & - \\
\hline YGTSS Total Tic Score & $\begin{array}{l}24.9(10.7) \\
24.5(15-32)\end{array}$ & - & - & - \\
\hline DOCS & $\begin{array}{l}23.9(16.3) \\
20.5(12-34)\end{array}$ & $\begin{array}{l}8.9(4.9) \\
9(5-12)\end{array}$ & -4.5 & $<0.0001$ \\
\hline ASRS-V & $\begin{array}{l}13.7(4.5) \\
19.5(17-22)\end{array}$ & $\begin{array}{l}6.1(2.7) \\
12(10-14)\end{array}$ & -6.3 & $<0.0001$ \\
\hline GAD-7 & $\begin{array}{l}10.5(5.8) \\
10(5-15)\end{array}$ & $\begin{array}{l}2.9(3.1) \\
3(0-5)\end{array}$ & -5.6 & $<0.0001$ \\
\hline PHQ-9 & $\begin{array}{l}10.9(6.0) \\
10.5(5-15)\end{array}$ & $\begin{array}{l}3.0(2.6) \\
3(1-4)\end{array}$ & -5.8 & $<0.0001$ \\
\hline
\end{tabular}

Note: *In each cell, mean (standard deviation) are listed above and median (interquartile range) below.

DOCS, and ASRS-V scores. SGI scores did not correlate with age or YGTSS total tic score.

Results of the hierarchical linear regression analysis, with SGI score as the dependent variable, are shown in Table 5. Only DOCS score significantly predicted mean SGI score in any model, with $\beta$ ranging from $1.03(p=0.044)$ in Model 2 to 1.41 in Model 5 ( $p=$ $0.001)$. The model inclusive of all five independent variables (Model 1) accounted for $37.9 \%$ of SGI score variance, and the simple linear regression model with DOCS as the independent variable (Model 5) accounted for $31.9 \%$ of SGI score variance. By AIC, Models 4 and 5 were superior to Models 1, 2, and 3.

\section{Discussion}

Here we demonstrate two important findings in adults with tic disorder. First, sensory hypersensitivity is common in adult tic disorder patients. Second, the extent of sensory hypersensitivity parallels obsessive-compulsive symptom burden, even after accounting for ADHD symptoms, tic severity, and sex. These findings will be discussed sequentially.

Findings from the current study show that sensory hypersensitivity is both prevalent and prominent in adults with tic disorders, replicating in a larger sample results observed by Sutherland-Owens et al. ${ }^{10}$ No established SGI score thresholds exist for delineating normal from abnormal sensory perception, but patients were $87.4 \%$ more likely to score higher on SGI than age- and sexmatched controls. Even patients who screened negative for both OCD and ADHD had significantly higher SGI scores relative to controls. As a caveat to this last 
Table 4 Correlation Matrix for Scales Within Patient Data Set

\begin{tabular}{|l|l|l|l|l|l|l|}
\hline & TTS $^{+}$ & PUTS & SGI & SPQ & DOCS & ASRS-V \\
\hline PUTS & 0.27 & & & & PHQ-9 \\
SGI & 0.28 & $0.34^{*}$ & & & & \\
SPQ & -0.23 & $-0.42^{*}$ & $-0.73^{* * *}$ & & & \\
DOCS & $0.44^{* *}$ & $0.35^{*}$ & $0.34^{*}$ & $-0.35^{*}$ & & \\
ASRS-V & $0.44^{* *}$ & 0.20 & $0.37^{*}$ & $-0.39 *$ & $0.43^{*}$ & \\
PHQ-9 & 0.21 & 0.15 & 0.24 & -0.27 & $0.57^{* * *}$ & $0.58^{* * *}$ \\
GAD-7 & $0.49 * *$ & 0.22 & 0.30 & $-0.40^{*}$ & $0.7 I^{* * *}$ & 0.32 \\
\hline
\end{tabular}

Notes: ${ }^{*} p<0.05,{ }^{*} p<0.01,{ }^{* * *} p<0.001 .{ }^{+}$YGTSS Total Tic Score.

Table 5 Hierarchical Regression Model Analysis

\begin{tabular}{|c|c|c|c|c|c|c|c|c|c|}
\hline Model & $\begin{array}{l}\text { Independent } \\
\text { Variables } \\
\text { (IVs) }\end{array}$ & $\begin{array}{l}\text { VIF } \\
\text { for } \\
\text { Model } \\
\text { IVs }\end{array}$ & $\begin{array}{l}\text { Shapiro-Wilk } \\
\text { Test for } \\
\text { Normality of } \\
\text { Model } \\
\text { Residuals }^{+}\end{array}$ & $\begin{array}{l}\text { Breusch- } \\
\text { Pagan Test } \\
\text { for Hetero- } \\
\text { scedasticity, } \\
\text { p-values }\end{array}$ & $\begin{array}{l}\text { Model F- } \\
\text { Value }\end{array}$ & $\begin{array}{l}\text { Model } \\
R^{2}\end{array}$ & $\Delta R^{2}$ & AIC & $\begin{array}{l}\text { IVs } \\
\text { That } \\
\text { Predict } \\
\text { Mean } \\
\text { SGI } \\
\text { Score }\end{array}$ \\
\hline $1^{\wedge}$ & $\begin{array}{l}\text { Age } \\
\text { Sex } \\
\text { DOCS } \\
\text { ASRS-V } \\
\text { TTS }\end{array}$ & $\begin{array}{l}1.13 \\
1.06 \\
1.68 \\
1.51 \\
1.66\end{array}$ & $0.97 p=0.5 \mathrm{I}$ & $p=0.23$ & $\begin{array}{l}F(5,25)=3.05 \\
p=0.028\end{array}$ & 0.379 & - & 308 & None \\
\hline 2 & $\begin{array}{l}\text { Sex } \\
\text { DOCS } \\
\text { ASRS-V } \\
\text { TTS }\end{array}$ & $\begin{array}{l}1.06 \\
1.58 \\
1.45 \\
1.59\end{array}$ & $0.97 p=0.63$ & $p=0.21$ & $\begin{array}{l}F(4,26)=3.85 \\
p=0.014\end{array}$ & 0.372 & $\begin{array}{l}\Delta R^{2}=0.07 \\
F(1,25)=0.279 \\
p=0.60\end{array}$ & 306 & $\begin{array}{l}\text { DOCS, } \\
\beta=1.03 \\
p=0.044\end{array}$ \\
\hline 3 & $\begin{array}{l}\text { DOCS } \\
\text { ASRS-V } \\
\text { TTS }\end{array}$ & $\begin{array}{l}1.58 \\
1.45 \\
1.50\end{array}$ & $0.98 p=0.92$ & $p=0.32$ & $\begin{array}{l}F(3,27)=5.03 \\
p=0.007\end{array}$ & 0.358 & $\begin{array}{l}\Delta R^{2}=0.014 \\
F(1,26)=0.566 \\
p=0.458\end{array}$ & 305 & $\begin{array}{l}\text { DOCS, } \\
\beta=1.05 \\
p=0.039\end{array}$ \\
\hline 4 & $\begin{array}{l}\text { DOCS } \\
\text { ASRS-V }\end{array}$ & $\begin{array}{l}1.34 \\
1.34\end{array}$ & $0.98 p=0.73$ & $p=0.23$ & $\begin{array}{l}F(2,28)=7.59 \\
p=0.002\end{array}$ & 0.352 & $\begin{array}{l}\Delta R^{2}=0.007 \\
F(I, 27)=0.291 \\
p=0.594\end{array}$ & 303 & $\begin{array}{l}\text { DOCS, } \\
\beta=1.15 \\
p=0.015\end{array}$ \\
\hline 5 & DOCS & - & $0.97 p=0.64$ & $p=0.41$ & $\begin{array}{l}F(1,29)=13.6 \\
p<0.001\end{array}$ & 0.319 & $\begin{array}{l}\Delta R^{2}=0.032 \\
F(1,28)=1.39 \\
p=0.248\end{array}$ & 303 & $\begin{array}{l}\text { DOCS, } \\
\beta=1.41 \\
p=0.001\end{array}$ \\
\hline
\end{tabular}

Notes: ^Same three outliers excluded from all models given Cook's $D>4 / n$ in Model I. ${ }^{+} p$-value $>0.05$ signifies inability to reject null hypothesis of normality of model residuals.

statement, subthreshold ADHD symptoms remain a potential confound because ASRS-V scores differed between this patient subset and their matched controls. Notably, the SGI displayed excellent internal reliability and good convergence with the SPQ in this sample. Of the four SGI domains, the Over-Inclusion and Hyperawareness domain corresponded most strongly with SPQ total, suggesting this domain best aligns with sensory hypersensitivity as captured by the SPQ. A larger patient sample is needed to more robustly investigate the psychometric properties of the SGI and SPQ measures in adults with tic disorders.

Using hierarchical linear regression analysis, we identified a significant relationship between sensory hypersensitivity and obsessive-compulsive symptoms, even after accounting for ADHD symptoms, tic severity, and sex. The only other study that administered the SGI to a TS sample did not observe any correlation between SGI score and obsessive-compulsive symptoms. ${ }^{10}$ This result, discrepant from our own, may be due to the other study's smaller 
sample size ( $n=18$ patients), heterogeneous cohort of both adults and children (as SGI has not been validated in minors), and/or use of a different OCD measure. ${ }^{10}$ In accord with our study, an investigation in 92 pediatric TS patients found those with sensory processing abnormalities had more obsessive-compulsive symptoms. ${ }^{12}$ A moderate correlation between sensory hypersensitivity and obsessive-compulsive symptoms $(r=0.39, p<0.001)$ has also been observed in a large $(n=274)$ sample of neurotypical adults, suggesting the interrelationship between these two domains is not confined to pathologic conditions. ${ }^{15}$

In the correlation analysis, severity of ADHD symptoms and extent of sensory hypersensitivity significantly correlated. However, no significant relationship between these variables emerged from the regression analysis. It has previously been shown that children with dual diagnoses of TS and ADHD manifest greater sensory perceptual dysfunction than those with TS alone. ${ }^{20}$ Additional study, likely involving a larger sample size, is needed to further examine the relationship between sensory hypersensitivity and ADHD symptoms in adults with tic disorders.

Sensory hypersensitivity and premonitory urge severity correlated modestly in our cohort. Two prior studies did not identify a relationship between premonitory urge and abnormal sensory perception in TS. ${ }^{10,12}$ However, in the first study, the young age of some of the participants (sample population ages ranged from 7 to 14 years) calls into question the reliability of their PUTS scores, ${ }^{12}$ since this scale has been shown to bear inconsistent results in populations younger than 10 years of age. ${ }^{27}$ In the second study, the sample size, smaller than that of the current investigation, may have been underpowered to identify a significant association between sensory hypersensitivity and premonitory urge. ${ }^{10}$ A separate study of 14 adult TS patients did not find any relationship between premonitory urge severity and (predominantly static) tactile detection thresholds, ${ }^{6}$ but this is not necessarily inconsistent with our findings showing a correlation between the clinical phenomena of premonitory urge and sensory hypersensitivity, given that both of these phenomena likely arise from higher-order sensory processing abnormalities. ${ }^{4,9}$ Notably, YGTSS total tic score did not correlate with either sensory hypersensitivity measure in our sample, suggesting that sensory hypersensitivity may be more tightly associated with premonitory urge than with tics. Identifying clinical associations of and potential contributors to premonitory urge is of great relevance because this symptom is more distressing than tics in many patients. ${ }^{1}$

The neurobiological basis of sensory hypersensitivity in TS is uncertain, but impaired sensory gating is strongly implicated. ${ }^{33-39}$ Sensory gating is the pre-conscious process by which irrelevant sensory input is filtered out, thereby facilitating attention to the most pertinent aspects of the sensory environment. ${ }^{25,40}$ Sensory gating is disrupted in TS, as demonstrated by multiple psychophysical and neurophysiologic studies. ${ }^{33-39,41}$ Tactile sensory gating impairment has been associated with deficient gammaamino-butyric acid levels in the sensorimotor cortex of TS patients. $^{7}$ While such findings are deepening insights into TS pathophysiology, the actual phenotypic manifestations and clinical relevance of impaired sensory gating in TS remain ambiguous. More specifically, it is uncertain whether sensory gating impairment gives rise to the subjective experience of sensory hypersensitivity. Thus, clarifying the nature and extent of sensory symptoms in TS is imperative to facilitate translation between clinical and physiologic research.

A growing body of evidence on sensory hypersensitivity and its neural substrates in OCD may offer important clues for TS research. ${ }^{16}$ As with TS, impaired sensory gating has been repeatedly observed in $\mathrm{OCD},{ }^{42-44}$ raising the possibility sensory gating dysfunction underlies sensory hypersensitivity in both disorders. Obsessive-compulsive symptoms are also associated with impaired sensory gating in neurotypical adults, implying a fundamental connection between these two phenomena. ${ }^{15,45}$ A precise understanding of the mechanisms responsible for altered sensory gating in TS and OCD is lacking. Sensory hypersensitivity in OCD has also been associated with increased volume of the sensorimotor cortex ${ }^{14}$ and with hyperactivation of the insula, a structure involved in integration of bodily sensations. ${ }^{46}$ Notably, the insula is key to urge formation in healthy individuals ${ }^{47,48}$ and to emergence of premonitory urge in TS. ${ }^{4}$ Thus, while significant knowledge gaps exist, current evidence suggests shared neural mechanisms underpin sensory hypersensitivity in both OCD and TS.

Future research should elucidate the extent to which sensory hypersensitivity is related to disorders of sensory modulation and sensory regulation already identified in pediatric TS populations. ${ }^{12,13,20}$ Longitudinal studies are needed to explore the potential role of sensory dysfunction in emergence of the broader TS phenotype during development and to quantify its impact on quality of life. And, clinical trials should be conducted to assess whether 
interventions targeting sensory dysfunction in other neurodevelopmental disorders ${ }^{49-51}$ can be effectively translated to tic disorder populations. ${ }^{52}$

Our study has several limitations. First, we did not screen for autism spectrum disorder, schizophrenia, or other lesscommon psychiatric comorbidities of TS. Prevalence of autism is estimated at $8.7 \%$ in adults with TS and lifetime prevalence of primary psychotic disorders at $0.8 \%{ }^{18,53}$ The impact of these conditions on study findings is likely low, but they do represent potential unmeasured confounders. Second, we employed self-report measures for OCD and ADHD symptoms rather than gold-standard, clinician-rated scales. That said, the DOCS and ASRS-V have both undergone rigorous validation and demonstrated good sensitivity in clinical populations. ${ }^{28,29}$ Third, the study sample size precluded development of more complex regression models for examining medication effect and interactions between variables. Lastly, the patient sample, consisting of adults with tic disorder referred to a tertiary care center, represented a more severe phenotype, potentially limiting the generalizability of our findings to the wider disorder spectrum. Furthermore, the study cohort was predominantly nonHispanic white, and thus is not representative across racial and ethnic groups.

In conclusion, study results confirm sensory hypersensitivity is prevalent and pronounced in adults with tic disorders, providing additional evidence this is a core feature of these disorders, one deserving of further research. Future studies investigating sensory hypersensitivity in TS should account for and explore the influence of obsessivecompulsive symptoms.

\section{Abbreviations}

TS, Tourette syndrome; SGI, Sensory Gating Inventory; SPQ, Sensory Perception Quotient; PUTS, Premonitory Urge to Tic Scale; DOCS, Dimensional ObsessiveCompulsive Scale; ASRS-V, Adult ADHD Self-Report Screening Scale for DSM-5; GAD-7, Generalized Anxiety Disorder 7; PHQ-9, Patient Health Questionnaire 9; YGTSS, Yale Global Tic Severity Scale.

\section{Acknowledgment}

The authors wish to thank Jacqueline Harris and Chelsea Mundy for serving as study coordinators.

\section{Author Contributions}

All others made substantial contributions to conception and design, acquisition of data, or analysis and interpretation of data; took part in drafting the article or revising it critically for important intellectual content; agreed on the journal to which the article will be submitted; gave final approval of the version to be published; and agree to be accountable for all aspects of the work.

\section{Funding}

The project was supported by CTSA award No. UL1 TR002243 from the National Center for Advancing Translational Sciences. Its contents are solely the responsibility of the authors and do not necessarily represent official views of the National Center for Advancing Translational Sciences or the National Institutes of Health.

\section{Disclosure}

David Isaacs reports grants from National Center for Advancing Translational Sciences during the conduct of the study. Harrison C. Walker reports grants from National Institutes of Health/National Institutes of Neurological Disorders and Stroke/BRAIN Initiative during the conduct of the study; and Dr. Walker has served as a clinical scientific consultant for Medtronic and Boston Scientific. Daniel O. Claassen received grant support from NIH/NINDS and NIA, Department of Defense, CHDI, Griffin Family Foundation, Michael J. Fox Foundation, Huntington Disease Society of America, AbbVie, Genentech/Roche, Neurocrine, Vaccinex, Teva Neuroscience, and received consulting fees from Alterity, Acadia, AbbVie Lundbeck, Teva Neuroscience, Spark Therapeutics, and payments for serving as Editor in chief of HD Insights. The authors report no other potential conflicts of interest for this work.

\section{References}

1. Cohen AJ, Leckman JF. Sensory phenomena associated with Gilles de la Tourette's syndrome. J Clin Psychiatry. 1992;53(9):319-323.

2. Houghton DC, Capriotti MR, Conelea CA, Woods DW. Sensory phenomena in Tourette syndrome: their role in symptom formation and treatment. Curr Dev Disord Rep. 2014;1(4):245-251. doi:10. 1007/s40474-014-0026-2

3. Cox JH, Seri S, Cavanna AE. Sensory aspects of Tourette syndrome. Neurosci Biobehav Rev. 2018;88:170-176. doi:10.1016/j.neubiorev. 2018.03.016

4. Cavanna AE, Black KJ, Hallett M, Voon V. Neurobiology of the premonitory urge in Tourette's syndrome: pathophysiology and treatment implications. J Neuropsychiatry Clin Neurosci. 2017;29 (2):95-104. doi:10.1176/appi.neuropsych.16070141

5. Belluscio BA, Jin L, Watters V, Lee TH, Hallett M. Sensory sensitivity to external stimuli in Tourette syndrome patients. Mov Disord. 2011;26 (14):2538-2543. doi: $10.1002 / \mathrm{mds} .23977$

6. Schunke O, Grashorn W, Kahl U, et al. Quantitative sensory testing in adults with Tourette syndrome. Parkinsonism Relat Disord. 2016;24:132-136. doi:10.1016/J.PARKRELDIS.2016.01.006 
7. Puts NAJ, Harris AD, Crocetti D, et al. Reduced GABAergic inhibition and abnormal sensory symptoms in children with Tourette syndrome. J Neurophysiol. 2015;114(2):808-817. doi:10.1152/jn.00060.2015

8. Ludlow AK, Wilkins AJ. Atypical sensory behaviours in children with Tourette's syndrome and in children with autism spectrum disorders. Res Dev Disabil. 2016;56:108-116. doi:10.1016/j.ridd.2016.05.019

9. Isaacs D, Riordan H. Sensory hypersensitivity in Tourette syndrome: a review. Brain Dev. 2020;42(9):627-638. doi:10.1016/j.braindev.20 20.06.003

10. Sutherland Owens AN, Miguel EC, Swerdlow NR. Sensory gating scales and premonitory urges in Tourette syndrome. Sci World J. 2011;11:736-741. doi:10.1100/tsw.2011.57

11. Miller LJ, Anzalone ME, Lane SJ, Cermak SA, Osten ET. Concept evolution in sensory integration: a proposed nosology for diagnosis. Am J Occup Ther. 2007;61(2):135-140. doi:10.5014/ajot.61.2.135

12. Weisman H, Parush S, Apter A, Fennig S, Benaroya-Milshtein N, Steinberg T. A study of sensory dysregulation in children with tic disorders. J Neural Transm. 2018;125(7):1077-1085. doi:10.1007/ s00702-018-1858-4

13. Soler N, Hardwick C, Perkes IE, et al. Sensory dysregulation in tic disorders is associated with executive dysfunction and comorbidities. Mov Disord. 2019;34(12):1901-1909. doi:10.1002/mds.27817

14. Subirà $\mathrm{M}$, Sato JR, Alonso $\mathrm{P}$, et al. Brain structural correlates of sensory phenomena in patients with obsessive-compulsive disorder. J Psychiatry Neurosci. 2015;40(4):232-240. doi:10.1503/jpn.140118

15. Ben-Sasson A, Podoly TY. Sensory over responsivity and obsessive compulsive symptoms: a cluster analysis. Compr Psychiatry. 2017;73:151-159. doi:10.1016/j.comppsych.2016.10.013

16. Houghton DC, Stein DJ, Cortese BM. Review: exteroceptive sensory abnormalities in childhood and adolescent anxiety and obsessive-compulsive disorder: a critical review. $J$ Am Acad Child Adolesc Psychiatry. 2020;59(1):78-87. doi:10.1016/j.jaac.2019.06.007

17. Ghanizadeh A. Sensory processing problems in children with ADHD, a systematic review. Psychiatry Investig. 2011;8(2):89-94. doi:10.4306/pi.2011.8.2.89

18. Hirschtritt ME, Lee PC, Pauls DL, et al. Lifetime prevalence, age of risk, and genetic relationships of comorbid psychiatric disorders in Tourette syndrome. JAMA Psychiatry. 2015;72(4):325. doi:10.1001/ jamapsychiatry.2014.2650

19. Huisman-van Dijk HM, van de Schoot R, Rijkeboer MM, Mathews CA, Cath DC. The relationship between tics, OC, ADHD and autism symptoms: A cross- disorder symptom analysis in Gilles de la Tourette syndrome patients and family-members. Psychiatry Res. 2016;237:138-146. doi:10.1016/j.psychres.2016.01.051

20. Jewers R, Staley D, Shady G. Sensory processing differences in children diagnosed with Tourette's disorder. Occup Ther Ment Health. 2013;29(4):385-394. doi:10.1080/0164212X.2013.848397

21. Spencer T, Biederman J, Harding M, Wilens T, Faraone S. The relationship between tic disorders and Tourette's syndrome revisited. J Am Acad Child Adolesc Psychiatry. 1995;34(9):1133-1139. doi:10.1097/00004583-199509000-00009

22. Harris PA, Scott KW, Lebo L, Hassan N, Lightner C, Pulley J. ResearchMatch: A national registry to recruit volunteers for clinical research. Acad Med. 2012;87(1):66-73. doi:10.1097/ACM.0b013e3 1823ab7d2

23. Harris PA, Taylor R, Minor BL, et al. The REDCap consortium: building an international community of software platform partners. J Biomed Inform. 2019;95:103208. doi:10.1016/j.jbi.2019.103208

24. Harris PA, Taylor R, Thielke R, Payne J, Gonzalez N, Conde JG. Research electronic data capture (REDCap)-a metadata-driven methodology and workflow process for providing translational research informatics support. $J$ Biomed Inform. 2009;42(2):377-381. doi:10.1016/j.jbi.2008.08.010

25. Hetrick WP, Erickson MA, Smith DA. Phenomenological dimensions of sensory gating. Schizophr Bull. 2012;38(1):178-191. doi:10.1093/ schbul/sbq054
26. Tavassoli T, Hoekstra RA, Baron-Cohen S. The Sensory Perception Quotient (SPQ): development and validation of a new sensory questionnaire for adults with and without autism. Mol Autism. 2014. doi:10.1186/2040-2392-5-29

27. Woods DW, Piacentini J, Himle MB, Chang S. Premonitory Urge for Tics Scale (PUTS): initial psychometric results and examination of the premonitory urge phenomenon in youths with tic disorders. J Dev Behav Pediatr. 2005;26(6):397-403. doi:10.1097/00004703-200512000-00001

28. Abramowitz JS, Deacon BJ, Olatunji BO, et al. Assessment of obsessive-compulsive symptom dimensions: development and evaluation of the dimensional obsessive-compulsive scale. Psychol Assess. 2010. doi: $10.1037 / \mathrm{a} 0018260$

29. Van de Glind G, van den Brink W, Koeter MWJ, et al. Validity of the adult ADHD self-report scale (ASRS) as a screener for adult ADHD in treatment seeking substance use disorder patients. Drug Alcohol Depend. 2013. doi:10.1016/j.drugalcdep.2013.04.010

30. Nunnally JC, Bernstein IH. Psychometric Theory. 3rd ed. New York: McGraw-Hill; 1994. doi:10.1037/018882

31. Conroy RM. What hypotheses do "nonparametric" two-group tests actually test? Stata J. 2012. doi:10.1177/1536867X1201200202

32. Akaike $\mathrm{H}$ Information theory and an extension of the maximum likelihood principle. Proceedings of the 2nd international symposium on information theory. Second Int Symp Inf Theory; 1973.

33. Castellanos FX, Fine EJ, Kaysen D, Marsh WL, Rapoport JL, Hallett M. Sensorimotor gating in boys with Tourette's syndrome and ADHD: preliminary results. Biol Psychiatry. 1996;39(1):33-41. doi:10.1016/0006-3223(95)00101-8

34. Swerdlow NR, Karban B, Ploum Y, Sharp R, Geyer MA, Eastvold A. Tactile prepuff inhibition of startle in children with Tourette's syndrome: in search of an "fMRI-friendly" startle paradigm. Biol Psychiatry. 2001;50(8):578-585. doi:10.1016/S0006-3223(01)011 64-7

35. Zebardast N, Crowley MJ, Bloch MH, et al. Brain mechanisms for prepulse inhibition in adults with Tourette syndrome: initial findings. Psychiatry Res - Neuroimaging. 2013;214(1):33-41. doi:10.1016/j. pscychresns.2013.05.009

36. Swerdlow NR. Update: studies of prepulse inhibition of startle, with particular relevance to the pathophysiology or treatment of Tourette Syndrome. Neurosci Biobehav Rev. 2013;37(6):1150-1156. doi:10. 1016/j.neubiorev.2012.09.002

37. Van Woerkom TCAM, Fortgens C, Van De Wetering BJM, Martens CMC. Contingent negative variation in adults with Gilles de la Tourette syndrome. J Neurol Neurosurg Psychiatry. 1988;51 (5):630-634. doi:10.1136/jnnp.51.5.630

38. Siniatchkin M, Kuppe A. Neurophysiological determinants of tic severity in children with chronic motor tic disorder. Appl Psychophysiol Biofeedback. 2011;36(2):121-127. doi:10.1007/s104 84-011-9155-0

39. Yordanova J, Dumais-Huber C, Rothenberger A. Coexistence of tics and hyperactivity in children: no additive at the psychophysiological level. Int J Psychophysiol. 1996;21:121-133. doi:10.1016/0167-8760 (95)00045-3

40. Cheng CH, Chan PYS, Niddam DM, Tsai SY, Hsu SC, Liu CY. Sensory gating, inhibition control and gamma oscillations in the human somatosensory cortex. Sci Rep. 2016;6:1-8. doi:10.1038/srep20437

41. Morand-Beaulieu S, Lavoie ME. Cognitive and motor event-related potentials in Tourette syndrome and tic disorders: A systematic review. Clin Neurophysiol. 2019;130(6):1041-1057. doi:10.1016/j. clinph.2018.10.022

42. Rossi S, Bartalini S, Ulivelli M, et al. Hypofunctioning of sensory gating mechanisms in patients with obsessive-compulsive disorder. Biol Psychiatry. 2005;57(1):16-20. doi:10.1016/j.biopsych.2004.09.023

43. Hashimoto T, Shimizu E, Koike K, et al. Deficits in auditory P50 inhibition in obsessive-compulsive disorder. Prog NeuroPsychopharmacol Biol Psychiatry. 2008;32(1):288-296. doi:10.101 6/j.pnpbp.2007.08.021 
44. Ahmari SE, Risbrough VB, Geyer MA, Simpson HB. Impaired sensorimotor gating in unmedicated adults with obsessive-compulsive disorder. Neuropsychopharmacology. 2012;37(5):1216-1223. doi:10.10 38/npp.2011.308

45. Ben-Sasson A, Podoly TY. Sensory habituation as a shared mechanism for sensory over-responsivity and obsessive-compulsive symptoms. Front Integr Neurosci. 2020;14. doi:10.3389/fnint.2020.00017.

46. Brown C, Shahab R, Collins K, et al. Functional neural mechanisms of sensory phenomena in obsessive-compulsive disorder. J Psychiatr Res. 2019;109:68-75. doi:10.1016/j.jpsychires.2018.11.018

47. Berman BD, Horovitz SG, Morel B, Hallett M. Neural correlates of blink suppression and the buildup of a natural bodily urge. Neuroimage. 2012;59 (2):1441-1450. doi:10.1016/j.neuroimage.2011.08.050

48. Jackson SR, Parkinson A, Kim SY, Schüermann M, Eickhoff SB. On the functional anatomy of the urge-for-action. Cogn Neurosci. 2011;2 (3-4):227-243. doi:10.1080/17588928.2011.604717

49. $\mathrm{Xu} \mathrm{W}$, Yao J, Liu W. Intervention effect of sensory integration training on the behaviors and quality of life of children with autism. Psychiatr Danub. 2019;31(3):340-346. doi:10.24869/psyd. 2019.340

50. Pfeiffer BA, Koenig K, Kinnealey M, Sheppard M, Henderson L. Effectiveness of sensory integration interventions in children with autism spectrum disorders: A pilot study. Am J Occup Ther. 2011;65 (1):76-85. doi:10.5014/ajot.2011.09205
51. Lin CL, Min YF, Chou LW, Lin CK. Effectiveness of sensory processing strategies on activity level in inclusive preschool classrooms. Neuropsychiatr Dis Treat. 2012;8:475-481. doi:10.2147/NDT.S37146

52. Soler N, Hardwick C, Perkes IE, Dossetor D, Bray P, Dale RC. An exploratory study into an adapted use of the alert program for tic disorder in children. Australas Psychiatry. 2019;27(2):144-151. doi:10.1177/1039856218815750

53. Darrow SM, Grados M, Sandor P, et al. Autism spectrum symptoms in a Tourette's disorder sample. J Am Acad Child Adolesc Psychiatry. 2017;56(7):610-617.e1. doi:10.1016/j.jaac.2017.05.002.

54. Ustun B, Adler LA, Rudin C, et al. The World Health Organization adult attention-deficit/hyperactivity disorder self-report screening scale for DSM-5. JAMA Psychiatry. 2017;74(5):520. doi:10.1001/ jamapsychiatry.2017.0298

55. Spitzer RL, Kroenke K, Williams JBW, Löwe B. A brief measure for assessing generalized anxiety disorder: the GAD-7. Arch Intern Med. 2006;166(10):1092. doi:10.1001/archinte.166.10.1092

56. Kroenke K, Spitzer RL, Williams JBW. The PHQ-9: validity of a brief depression severity measure. J Gen Intern Med. 2001;16 (9):606-613. doi:10.1046/j.1525-1497.2001.016009606.x

57. Leckman JF, Riddle MA, Hardin MT, et al. The Yale global tic severity scale: initial testing of a clinician-rated scale of tic severity. J Am Acad Child Adolesc Psychiatry. 1989;28(4):566-573. doi:10.10 97/00004583-198907000-00015
Neuropsychiatric Disease and Treatment

\section{Publish your work in this journal}

Neuropsychiatric Disease and Treatment is an international, peerreviewed journal of clinical therapeutics and pharmacology focusing on concise rapid reporting of clinical or pre-clinical studies on a range of neuropsychiatric and neurological disorders. This journal is indexed on PubMed Central, the 'PsycINFO' database and CAS, and
Dovepress

is the official journal of The International Neuropsychiatric Association (INA). The manuscript management system is completely online and includes a very quick and fair peer-review system, which is all easy to use. Visit http://www.dovepress.com/testimonials.php to read real quotes from published authors. 